\title{
Uniportal video-assisted thoracoscopic surgery right upper lobectomy by bronchus-artery-vein procedure: a case report
}

\author{
Tianxiang Chen ${ }^{1}$, Hang Zhao ${ }^{2}$, Junwei Ning ${ }^{1}$, Xiaocheng Zhang ${ }^{3}$, Qingquan Luo ${ }^{1}$ \\ ${ }^{1}$ Shanghai Lung Cancer Center, Shanghai Chest Hospital, Shanghai Jiao Tong University, Shanghai, China; ${ }^{2}$ Department of Thoracic Surgery, \\ Dongyang People's Hospital, Dongyang, China; ${ }^{3}$ Department of Pulmonary Medicine, The First Affiliated Hospital, Wenzhou Medical University, \\ Wenzhou, China \\ Correspondence to: Qingquan Luo. Shanghai Lung Cancer Center, Shanghai Chest Hospital, Shanghai Jiao Tong University, 241 Huai Hai Road, \\ Shanghai 200030, China. Email: luoqingquan@hotmail.com; Tianxiang Chen. Shanghai Lung Cancer Center, Shanghai Chest Hospital, Shanghai \\ Jiao Tong University, 241 Huai Hai Road, Shanghai 200030, China. Email: txchen@shsmu.edu.cn.
}

\begin{abstract}
The learning curve for uniportal video-assisted thoracoscopic surgery (VATS) lobectomy is much longer than multi-portal VATS lobectomy due to higher surgical requirement and understanding for both surgeon and assistants. To perform same lobectomy with different procedure is beneficial for the better understanding of anatomy under the unique confronting thorascopic view of uniportal VATS. Here we are going to share a case who received uniportal VATS right upper lobectomy (RUL) with the division order of bronchus-artery-vein (B-A-V) as a unique procedure. This procedure aim to show important anatomical structures of right upper lobe from both anterior and posterior ways respectively. A 64 years old female patient presented with an asymptomatic lesion of right upper lobe lesion on chest CT-scan during routine physical exam. She underwent uniportal VATS RUL after preoperative evaluation for the peripheral lung cancer. No perioperative complications were found and patient was discharged on postoperative day 3 . The Pathology report revealed the dominant tumor subtype was lepidic invasive adenocarcinoma; the tumour size was $3.7 \mathrm{~cm} \times 3 \mathrm{~cm}$; bronchus stump margin was negative. The B-A-V procedure for uniportal VATS RUL is based on "First hard then soft" concept, it's a safe and educational procedure providing satisfactory exposure for surgeons.
\end{abstract}

Keywords: Uniportal; video-assisted thoracoscopic surgery (VATS); right upper lobectomy (RUL); bronchusartery-vein (B-A-V) procedure; case report

Received: 24 July 2021; Accepted: 10 November 2021; Published: 30 January 2022.

doi: $10.21037 /$ shc-21-19

View this article at: https://dx.doi.org/10.21037/shc-21-19

\section{Introduction}

Uniportal video-assisted thoracoscopic surgery (VATS) lobectomy is a minimal invasive technique first introduced by Diego Gonzalez-Rivas (1). This technique requires highly trained surgical skill to apply on patients. Therefore, the experience of surgeon is the crucial factor for safe and smooth surgery process. Pre-operative assessment of patient selection is one of the most key elements for a satisfactory perioperative outcome.

Uniportal VATS lobectomy has been developing and spreading around the world especially Europe and Asia (2).
Learning curve for uniportal VATS lobectomy was reported from different centers in the world and Arthur introduced that it took 140 procedures to master the approach which was much longer than multi-portal approach (3). Right upper lobectomy (RUL) was the most common procedure $(42 \%)$ reported from a high volume center (4), therefore we decided to develop this case video to help the education for thoracic surgical trainees.

Single-direction thoracoscopic lobectomy as a concept was introduce by Liu in 2010 (5), his technique influenced many surgeons practicing VATS lobectomy in Asia. The bronchus-artery-vein (B-A-V) procedure here we presented 

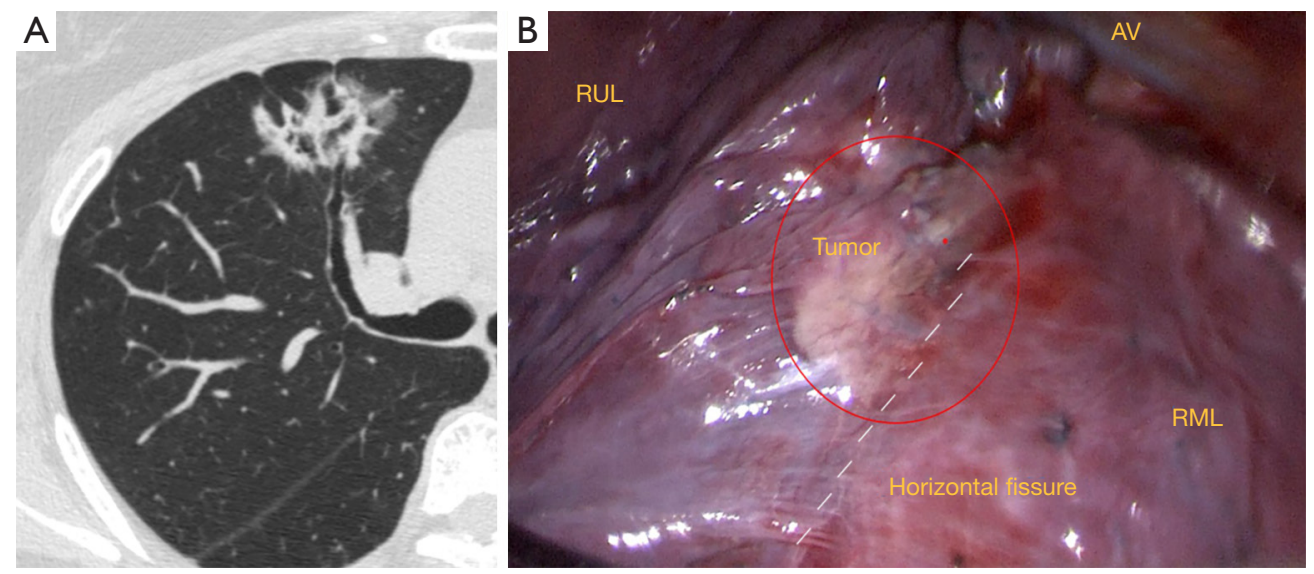

Figure 1 CT imagine of lesion (A) and thorascopic view of lesion (B). RUL, right upper lobe; AV, azygous vein; RML, right middle lobe.

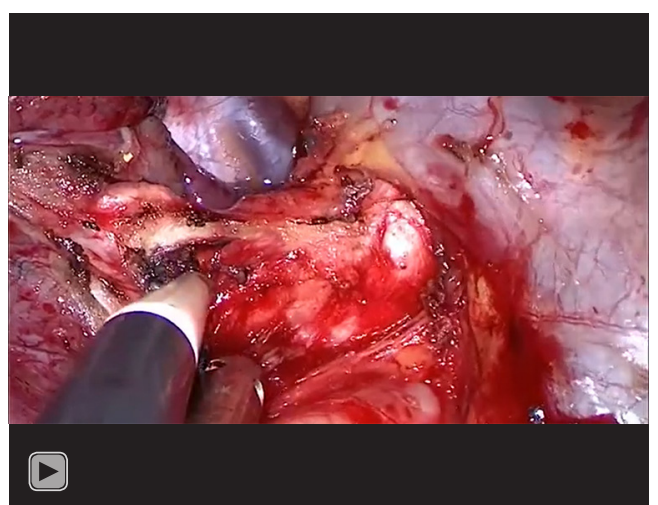

Video 1 Surgical procedure of B-A-V for Uniportal VATS right upper lobectomy. B-A-V, bronchus-artery-vein; VATS, videoassisted thoracoscopic surgery.

was a different way from single-direction concept. We present the following article in accordance with the CARE reporting checklist (available at https://shc.amegroups.com/ article/view/10.21037/shc-21-19/rc).

\section{Case presentation}

A 64-year-old female presented with an incidental finding of a right upper lobe lesion on chest CT-scan, during routine physical examination. No history of smoking and alcohol abuse were presented, and no special existing comorbidities was presented to be considered. PET CT imaging indicated a $37 \mathrm{~mm} \times 31 \mathrm{~mm}$, T2aN0M0 lesion in the right upper lobe which was close to the horizontal fissure (Figure 1). Pulmonary function was assessed via formal spirometry with a FEV1 of 2.16 (97.4\% predicted), an FEV1/FVC ratio of $104.1 \%$. Spirometry was tested for pulmonary function. Echocardiography was accessed for heart function. To rule out for coronary heart disease, treadmill exercise test was also done. For the preoperative staging, the patient took positron emission tomography-CT (PET-CT) scan and brain magnetic resonance imaging (MRI) beside high resolute chest CT scan. Since the chest CT scan showed the lesion was a mixed ground glass opacity (mGGO) and PET/CT didn't report lymph node involvement, we did not perform E-BUS or mediastinoscopy on patient.

Anaesthesia and positioning is as standard as for VATS lobectomy as introduced by Valerio et al (6). Double-lumen endotracheal intubation is applied for general anaesthesia to allow single lung ventilation. Paravertebral block was used for post-operative analgesia of this patient. After a $3 \mathrm{~cm}$ anterior incision at the level of the 5th intercostal space was made, we put the thoracoscope at the top, leaning on the double joint oval clamp to ease assistant's fatigue during holding the thoracoscope. Energy instruments suction aspirator and staplers were put under the top angle crossed by thoracoscope and double joint oval clamp.

The B-A-V operative steps for RUL (Video 1):

The B step: (I) oblique fissure; (II) right upper lobe bronchus (RULB) (Figure 2);

The A step: (III) posterior segmental artery (A2); (IV) anterior and apical segmental trunk (TAA) (Figures 3,4);

The V step: (V) right upper lobe vein (RULV); (VI) horizontal fissure.

After the lobe is removed using a protective bag, a lobe selective systematic lymph node dissection was done including the paratracheal lymph nodes (station 2 and 4) 


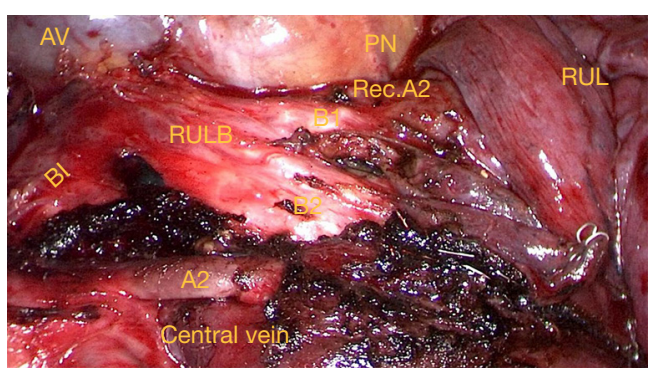

Figure 2 Posterior view of RUL hilar anatomy after opening the oblique fissure. AV, azygous vein; PN, phrenic nerve; Rec.A2, recurrent A2; BI, bronchus intermediate; RULB, right upper lobe bronchus.

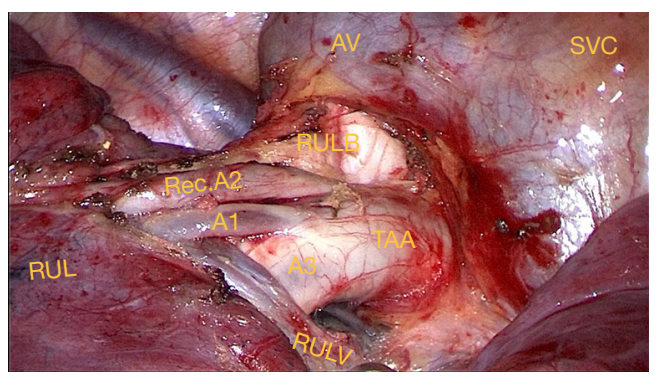

Figure 3 Anterior view of RUL hilar anatomy. AV, azygous vein; PN, phrenic nerve; Rec.A2, recurrent A2; BI, bronchus intermediate; RULB, right upper lobe bronchus; SVC, superior vena cava; TAA, anterior and apical segmental trunk; RULV, right upper lobe vein.

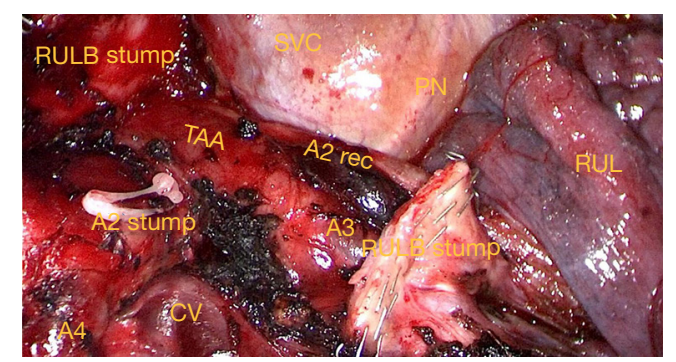

Figure 4 Posterior view of Anterior and apical segmental trunk. PN, phrenic nerve; Rec.A2, recurrent A2; BI, bronchus intermediate; RULB, right upper lobe bronchus; SVC, superior vena cava; TAA, anterior and apical segmental trunk; $\mathrm{CV}$, central vein. and subcarinal lymph nodes (station 7). A single $28 \mathrm{~F}$ chest tube is placed through the incision before closing.

No perioperative complications were found and patient was discharged on postoperative day 3. Pathology report: lepidic invasive adenocarcinoma; the tumour size was $3.7 \mathrm{~cm} \times 3 \mathrm{~cm}$; bronchus stump margin was negative. All procedures performed in studies involving human participants were in accordance with the ethical standards of the institutional and national research committee and with the Helsinki Declaration (as revised in 2013). Written informed consent was obtained from the patient for publication of this study and any accompanying images. A copy of the written consent is available for review by the editorial office of this journal.

\section{Discussion}

Minimal invasive surgery has been developing fast during last decade because of the high incidence of early stage lung cancer worldwide (7). Different operative approach for uniportal VATS RUL through the transaxillary incision through subxiphoid incision or conventional intercostal incision (4th or 5 th intercostal space) $(8,9)$. Here we described the $\mathrm{B}-\mathrm{A}-\mathrm{V}$ procedure with a edited video with the intention to show both anterior and posterior aspect view of hilar structure for right upper lobe, to help the surgical trainee to understand more about the anatomical details for this operation. In addition, the advantage of this procedure is when the fissure was difficult to open, and hilar lymph node were too hard to remove from the anterior mediastinal side, first division of RULB can bring great surgical space. The essential concept is to remove the only hard structure first which is the bronchus, left all the soft structures including arteries and veins to deal behind. This 'first hard then soft' strategy gives surgeon safe space and flexibility to control the hilar structure without risking great intraoperative hemorrhage. This $\mathrm{B}-\mathrm{A}-\mathrm{V}$ procedure for RUL just is a manifestation for this "first hard then soft" concept.

In conclusion, uniportal VATS RUL by B-A-V procedure has advantages of exposure in applicable situation. Surgeons in training need to master certain techniques with appropriate incision chosen to perform. 


\section{Acknowledgments}

Funding: This article was supported by Shanghai Science and Technology Committee (No. 18411966100), Shanghai Talent Development Fund (No. 2019073), Shanghai Natural Science Foundation (Grant No. 18ZR1435100), Shanghai "Rising Stars of Medical Talent" Youth Development Program (Specialist Program), and Morningstar award program for outstanding young scholars of Shanghai Jiaotong University.

\section{Footnote}

Reporting Checklist: The authors have completed the CARE reporting checklist. Available at https://shc.amegroups.com/ article/view/10.21037/shc-21-19/rc

Peer Review File: Available at https://shc.amegroups.com/ article/view/10.21037/shc-21-19/prf

Conflicts of Interest: All authors have completed the ICMJE uniform disclosure form (available at https://shc.amegroups. com/article/view/10.21037/shc-21-19/coif). QL serves as an unpaid Associate Editor-in-Chief of Shanghai Chest from February 2021 to January 2023. The other authors have no conflicts of interest to declare.

Ethical Statement: The authors are accountable for all aspects of the work in ensuring that questions related to the accuracy or integrity of any part of the work are appropriately investigated and resolved. All procedures performed in studies involving human participants were in accordance with the ethical standards of the institutional and/or national research committee(s) and with the Helsinki Declaration (as revised in 2013). Written informed consent was obtained from the patient for publication of this Case report and any accompanying images. A copy of the written consent is available for review by the editorial office of this journal.

Open Access Statement: This is an Open Access article distributed in accordance with the Creative Commons Attribution-NonCommercial-NoDerivs 4.0 International License (CC BY-NC-ND 4.0), which permits the noncommercial replication and distribution of the article with the strict proviso that no changes or edits are made and the original work is properly cited (including links to both the formal publication through the relevant DOI and the license). See: https://creativecommons.org/licenses/by-nc-nd/4.0/.

\section{References}

1. Gonzalez-Rivas D. VATS lobectomy: surgical evolution from conventional VATS to uniportal approach. ScientificWorldJournal 2012;2012:780842.

2. Bertolaccini L, Batirel H, Brunelli A, et al. Uniportal video-assisted thoracic surgery lobectomy: a consensus report from the Uniportal VATS Interest Group (UVIG) of the European Society of Thoracic Surgeons (ESTS). Eur J Cardiothorac Surg 2019;56:224-9.

3. Vieira A, Bourdages-Pageau E, Kennedy K, et al. The learning curve on uniportal video-assisted thoracic surgery: An analysis of proficiency. J Thorac Cardiovasc Surg 2020;159:2487-2495.e2.

4. Hernandez-Arenas LA, Lin L, Purmessur RD, et al. Uniportal video-assisted thoracoscopic early learning curve for major lung resections in a high volume training center. J Thorac Dis 2018;10:S3670-7.

5. Liu L, Che G, Pu Q, et al. A new concept of endoscopic lung cancer resection: Single-direction thoracoscopic lobectomy. Surg Oncol 2010;19:e71-7.

6. Perna V, Torrecilla JA, Carvajal AF, et al. Uniportal right upper video-assisted thoracoscopic surgery lobectomy: safe and feasible. J Vis Surg 2016;2:160.

7. Chen T, Luo J, Gu H, et al. Impact of Solid Minor Histologic Subtype in Postsurgical Prognosis of Stage I Lung Adenocarcinoma. Ann Thorac Surg 2018;105:302-8.

8. Argueta AJO, Cañas SRR, Abu Akar F, et al. Subxiphoid approach for a combined right upper lobectomy and thymectomy through a single incision. J Vis Surg 2017;3:101.

9. Shen Y, Zhang Y, Sun J, et al. Transaxillary uniportal video assisted thoracoscopic surgery for right upper lobectomy. J Thorac Dis 2018;10:E214-7.

doi: $10.21037 /$ shc-21-19

Cite this article as: Chen T, Zhao H, Ning J, Zhang X, Luo Q. Uniportal video-assisted thoracoscopic surgery right upper lobectomy by bronchus-artery-vein procedure: a case report. Shanghai Chest 2022;6:9. 